\title{
Children's Lived Spaces in Suburban Taiwan During the 1960s
}

\author{
Mengchun Chiang, Duquesne University \\ Email: chiangm@duq.edu
}

\section{Abstract}

This study aims to portray children's lived spaces in rural Taiwan during the 1960s. Taiwan started to develop into a prosperous and industrialized country with a stronger and dynamic economy during the 1960s while it maintained an authoritarian, single-party government. Today, Taiwan has transformed into a country that is not only economically developed, but also socially Westernized. The lived spaces of children in suburban Taiwan have gone through a drastic change during the last 50 years. This study attempts to provide descriptions of children's lived space during the 1960s as a different way that space could be lived in comparison to the present westernized space and gives insights into an Other kind of the lived space of society today. I interviewed two native Taiwanese adults who were about 10 years old during the 1960s. I asked them to draw a picture of their childhood home and to describe their everyday experience in that space. Both participants described a childhood home similar to a traditional san-ho-yuan architecture that has an open space in the center of a three-wing building. The architecture of children's lived spaces in rural Taiwan during the 60s invites intimate familial encounters, engagements with nature and domestic animals, and communal activities for children. With the narratives of the participants, attention was drawn to how children are living in the present day Taiwanese architecture where they are provided with a separate and distinct lived space that does not allow for close and intimate encounters with adults, other children, and nature. The concluding remark underlies the challenges of forming a sense of identity in the given lived space that children face today.

\section{Introduction}

When thinking of space, we typically consider its geometrical dimension. Thinking of space as geometrical reduces it to numbers and measures that are devoid of meaningful human elements. Therefore, in order to understand the meaningfulness of situated human existence, it is much more informative to inquire into people's experience with lived space rather than research an abstract geometrical space. Minkowski (1970) writes, "We live and act in space, and our personal lives, as 
well as the social life of humanity, unfolds in space” (p. 400). The interpersonal and social dimensions of space can only manifest when it is lived. Merleau-Ponty (1962) considers lived space as a primordial structure that saturates consciousness without conscious reflection. Along the same line, Benswanger (1979) suggests that lived space is "an essential aspect of human existence” (p. 116). Simms (2008b) also notes that "it is by means of space that being exists" (p. 32). Understanding space phenomenologically rather than geometrically or physiologically seems to be fundamental to understanding the meaning of human existence. Moreover, understanding the meanings of lived spaces through children's eyes allows for psychological understandings of various dimensions in human life. In Benswanger's (1979) words, describing “how a young child learns to inhabit his 'vital space,' how he makes himself at home in the world and begins to elaborate on the spatial dimensions of his experience," may shed light on the "understanding of the psychological implications of spatial experience at all stages of human life” (p. 115). Thus, understanding space as a fundamental aspect of human existence has inspired this study. In other words, this study is an attempt to describe children's lived spaces as a fundamental aspect of children's life in rural Taiwan during the 1960s. Childhood descriptions are illuminated with drawings in order to illustrate the situated lived spaces with meanings. Various dimensions of lived meanings of the childhood lived spaces in 1960s Taiwan will be made explicit and discussions will consider how lived-space influences children's development through the narratives of the participants comparing childhood space in the 1960s and the present day Taiwan.

\section{Locating Taiwan in the 1960s}

Taiwan has had a long history of colonization. The Portuguese "discovered" Taiwan in the $16^{\text {th }}$ century and named Taiwan "Ila Formosa," which means “a beautiful Island.” In the $17^{\text {th }}$ century, the Netherlands and Spain colonized different parts of Taiwan. Afterwards, the Netherlands expelled Spain and occupied Taiwan for 30 years in the middle of the $17^{\text {th }}$ century. In the late $19^{\text {th }}$ century, Taiwan was ceded to Japan as a result of the war between Japan and the Republic of China (ROC). Japan lost the battle in the end of WWII and returned Taiwan to the ROC government in 1945. The years between 1945 and 1960 are referred to as the post World War era for Taiwan. A major event happened in 1949. The communist government took over mainland China and announced the establishment of the People's Republic of China (PRC), or, the current Chinese government. In the meantime, the ROC government moved to Taiwan and announced the order of martial law with the hope to recover mainland China. Due to the order of martial law, social campaigns were suppressed and thus the social movement in the 1960s was relatively quiet in Taiwan. Although the social movement was comparatively quiet, the economic situation in Taiwan continued to progress in the 1960s. The general workforce was dominated by labor-intensive jobs during the 1960s in Taiwan. In the suburbs, agricultural labor is a predominant part of everyday life. Due to the mass participation in labor-intensive work, the first export processing zone in Asia was built in Taiwan and became internationally well-known. After the export processing zone was built, Taiwan maintained a two-digit economic progress rate until the first oil crisis. Recently, Taiwan has gone from a developing country to a developed country. Politically, the ROC government declared the end of martial law in 1987 and put in motion the present mature democratic government in Taiwan. Economically, Taiwan has gone from labor-intensive industries to engaging in technologies such as bicycle manufacturing, biotechnology and semiconductor device fabrication. Overall, the current society of Taiwan is 
much more modernized and Westernized in the 21st century than fifty years ago.

\section{Methods and Participants}

I interviewed two Taiwanese adults who were about 10 years old during the 1960s and living in Taiwan. Interviewees were recruited verbally from elders in my family and a friend's family. I interviewed Li-Mai ${ }^{1}$ by phone and Chi-Lin in person. I first asked the participants to draw a sketch of their childhood home and neighborhood, and then I had them describe their everyday experience as 10-year-old children living in the space they drew. Li-Mai drew her childhood home and sent it to me via email prior to our interview. I asked only questions for clarification in the beginning of the interview and then made specific inquiries regarding where the participants played as children in their homes, the presence of others, the participants' commute to school, seasonal events in the community, the participants' impression of the change of their neighborhood and their sense of how this change of space influences children in the present day. The interview was informed by Maurice Merleau-Ponty’s (1962) notion of children’s lived space. In a similar manner that Simms (2008a) understands children's lived space as the places they claim in the neighborhood, this project embarked as a phenomenological exploration of children's lived spaces during the 1960s in Taiwan.

I took an additional step to analyze the interview using the three-phase structure Benswager (1979) proposed for understanding children's lived space. When I re-listened to the interviews, I paid specific attention to developmental, phenomenological, and psychological concepts in the participants' discourse. I incorporated this three-phase structure (Benswanger, 1979) to anchor the representation of the participants' childhood lived space within the themes of space (attuned space, activity, spatial characteristics, and organization), the perspectives of inhabited space (self-act-world), and modes of relatedness (presence and transcendence).

\section{Voices of the Participants}

Both participants, Chi-Lin and Li-Mai, were native Taiwanese as they were born and have lived most of their lives in Taiwan. As a child, Chi-Lin lived in a suburb of Tainan County and Li-Mai grew up in a suburb of Taichung County in Taiwan. Both Tainan and Taichung County still maintain some traditional values, practices, and cultural beliefs in the suburban areas in the present day. After drawing their childhood homes and neighborhoods, both Chi-Lin and Li-Mai began by narrating an explanation of the structure of their childhood houses since they are very different from the modern architectures. San-ho-yuan is a traditional Chinese architecture of a three-section compound that includes a central building with two wings attached perpendicular to either side (see figure $1 \& 2$ for pictures of san-ho-yuan). One san-ho-yuan building usually accommodates many different households that are related to each other on the father's side of the family. There is always an open space in the middle of a traditional san-ho-yuan architecture that may be used for drying crops, gatherings, children or adults’ play, etc. 


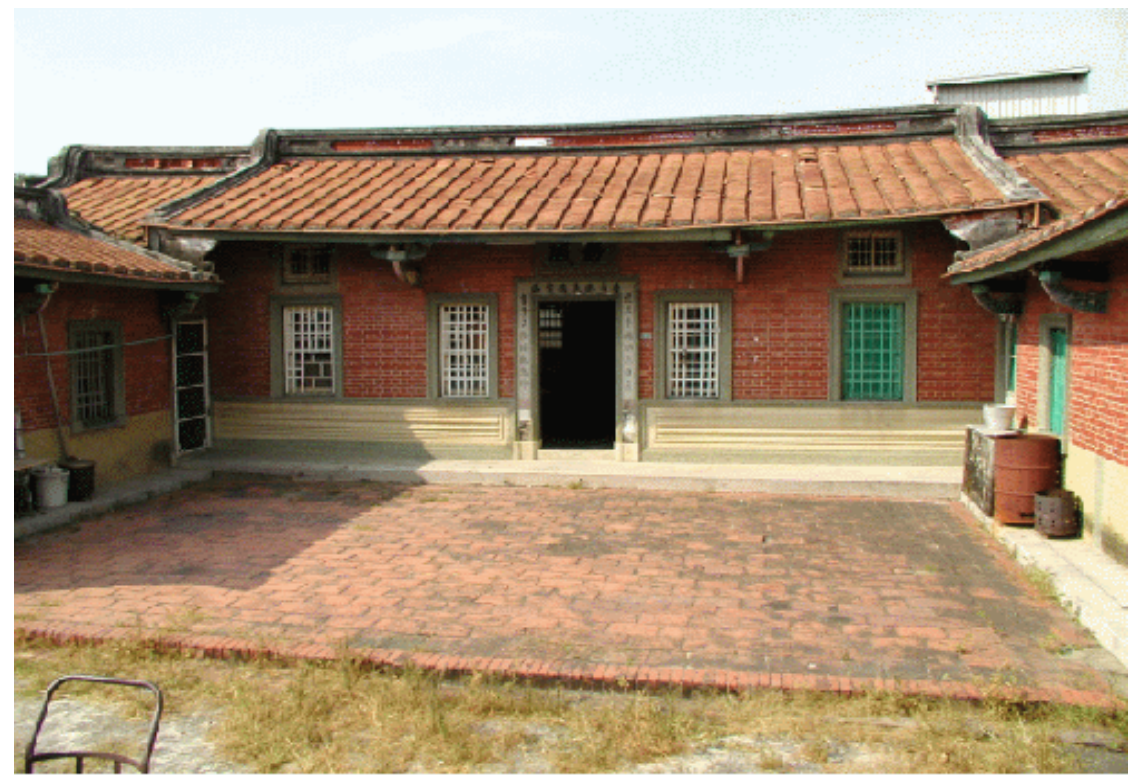

Figure 1. San-ho-yuan front view

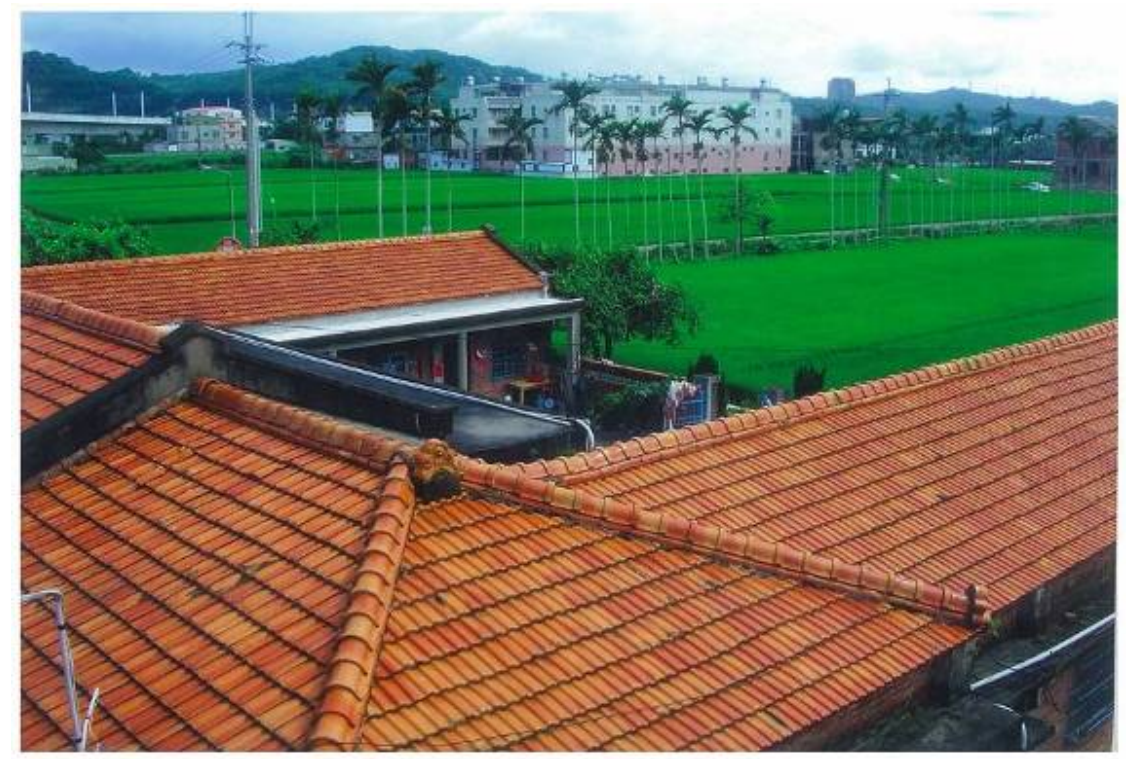

Figure 2. San-ho-yuan from an elevated view with farms and nature. 


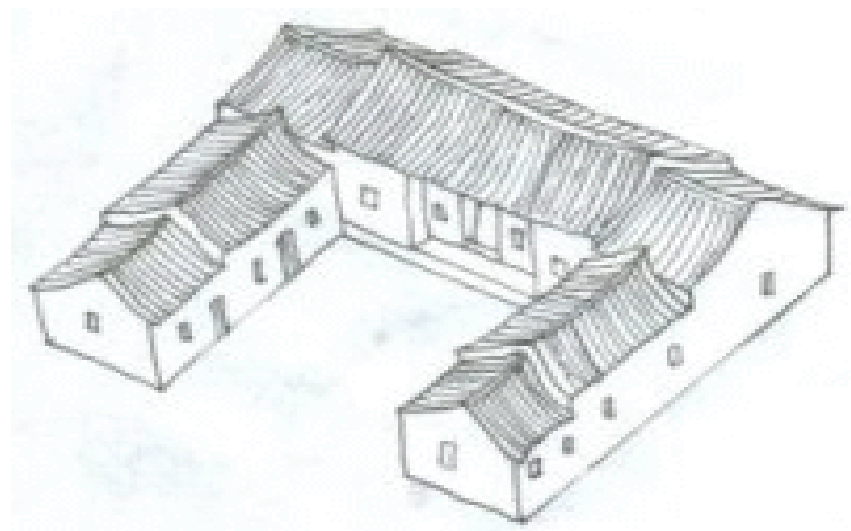

Figure 3. General floor plan of san-ho-yuan

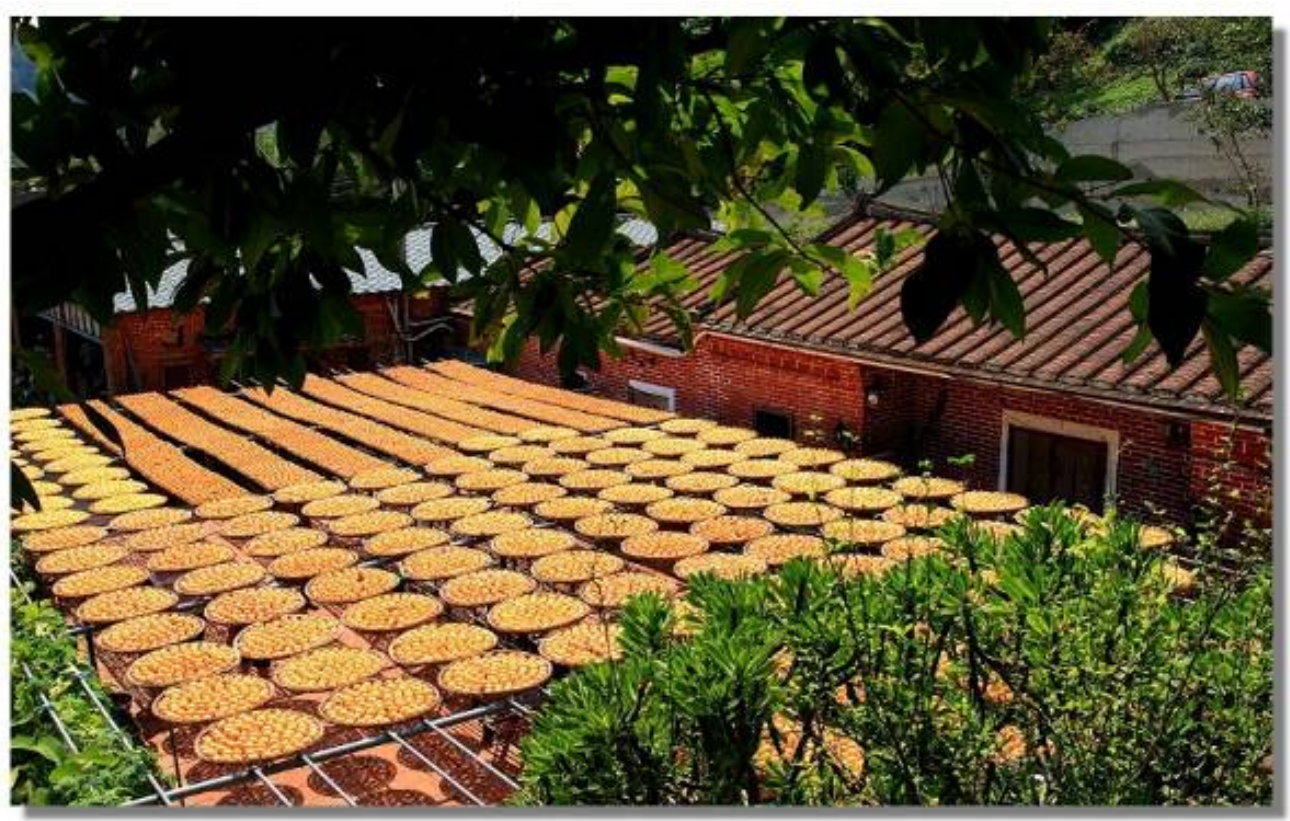

Figure 4. The open space of san-ho-yuan was used to dry vegetables like corn, sweet potatoes, beans, depending on the harvests.

Between the two participants, only Chi-Lin lived in a san-ho-yuan architecture as a child, but both Chi-Lin and Li-Mai lived in a house that was surrounded by different households of relatives and had the feature of an open space in the center of the architecture. The structure of the houses is important because the space is lived in with the latent intentionality of the physical structure of a house. Descriptions of Chi-Lin and Li-Mai's childhood experiences reveal that children's lived spaces in suburban Taiwan during the 1960s shaped their experiences with their extended family in ways that are very different from what is typical in a Westernized lived space of today. In general, Chi-Lin and Li-Mai indicated that the space of their childhood houses included more intimate interpersonal encounters, especially with their extended family members and neighbors. Li-Mai said, "We lived with the extended family, brothers of my father all lived with us." Chi-Lin also noted, "We lived with extended family of three generations, mostly with my father's 
relatives.” Since the whole extended family lived together, it was also common for older children or grandparents to take care of younger children in the family while their parents worked in agriculture.

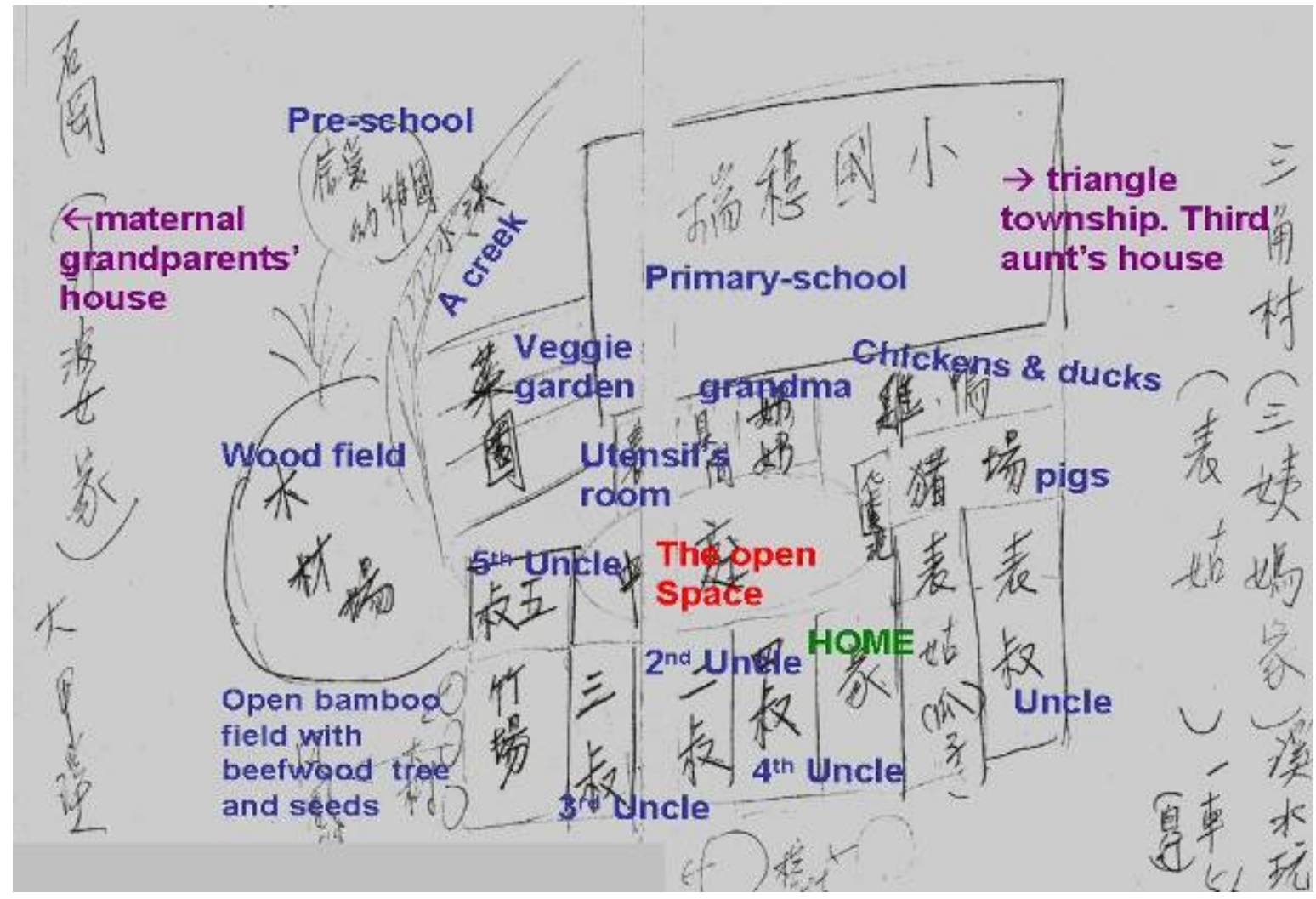

Figure 5. Li-Mai’s drawing for her childhood lived space

In Li-Mai's drawing (figure 5), her family home is located among other households of her family (grandma, uncles, and an aunt), natural fields (bamboo, forests, veggie garden), family-bred domestic animals (pigs, chickens, and ducks), and a tool shed. In the center of the households is an open space that can be accessed from every household's back door. She found it very difficult to recall memories only from "inside" her family home. Rather, her understanding of her childhood "roaming space” includes all of her extended families' households, the animals, the surrounding natural area, and even the utensil rooms. She described the nearby creek, the playground of the pre-school and the elementary school as part of her childhood lived space, although she saw the creek and the school spaces as more of a public space than her family household spaces. That is, Li-Mai described the totality of her extended family space as her "childhood home" and in contrast, the school space and the creek were places she ventured into as a child. Other, more distant places such as her maternal grandparents' house and another aunt's house in a more distant township were also considered to be the part of her childhood lived space, although she acknowledged the larger physical distances. Li-Mai shared that she and her childhood friends (composed of her cousins and other kids in the neighborhood) used to ride their bicycle everywhere. Places like the maternal grandmothers' house and the aunt's house in a different township were seen as farther away because they were usually too distant to reach by bicycle. 


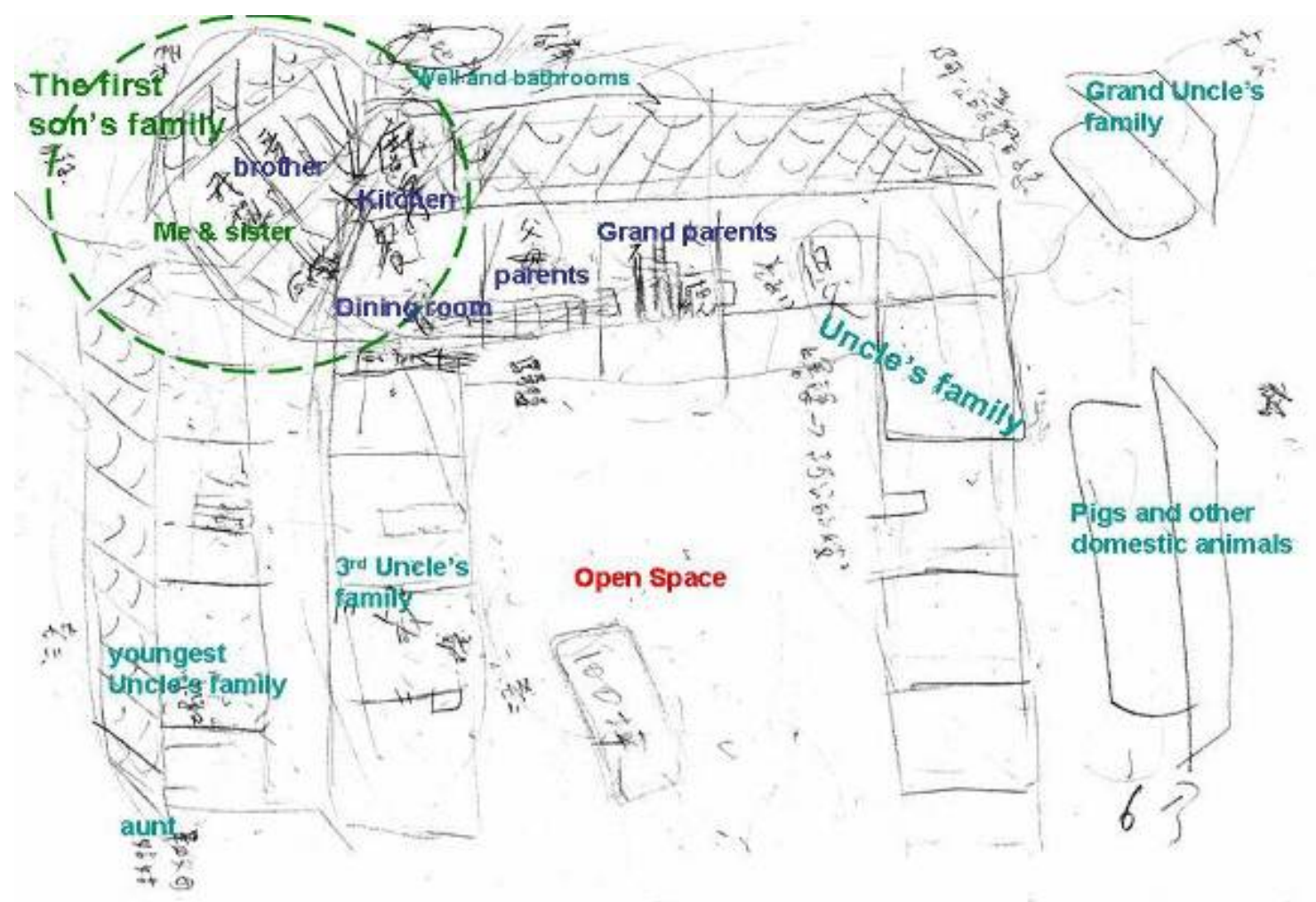

Figure 6. Chi-Lin's drawing of her childhood lived space

Chi-Lin's drawing of her childhood space (see figure 6) represents a traditional form of san-ho-yuan architecture. In addition to the three-section compound of the san-ho-yuan architecture, Chi-Lin drew two additional buildings on the right skirt of the compound that housed her extended families who could not fit in to the main san-ho-yuan structure. She identified her room that she shared with her sister, her brother's room, and her parents' room. However, when describing her average day as a 10-year-old, Chi-Lin recalled very little activity "inside" her own room because her childhood roaming space was not limited to her room nor the space assigned to her immediate family. She remembered many interactions with her grandmother, her aunts, and other people in the house when she was at home. She also considered going in and out of adults' bedrooms and other families' homes to be a normal course of action. The right skirt of the compound housed Chi-Lin's family, two of her uncles and her aunt. She indicated that she was closer to the households on the right skirt because they shared the kitchen and the dining room. The center and the left skirt of the san-ho-yuan housed Chi-Lin's grandparents and another uncle's family. There was another addendum on the back of the left skirt that housed her great uncle's family. The henhouse and spaces for other domestic animals are also on the left skirt of the san-ho-yuan in Chi-Lin's drawing. Like all traditional san-ho-yuan architecture, the san-ho-yuan of Chi-Lin's childhood space also has an open space in the center of the buildings. She indicated that this space is for children's play, adults' social activity, and in the summer, they used this space to dry the vegetables that they grew. 


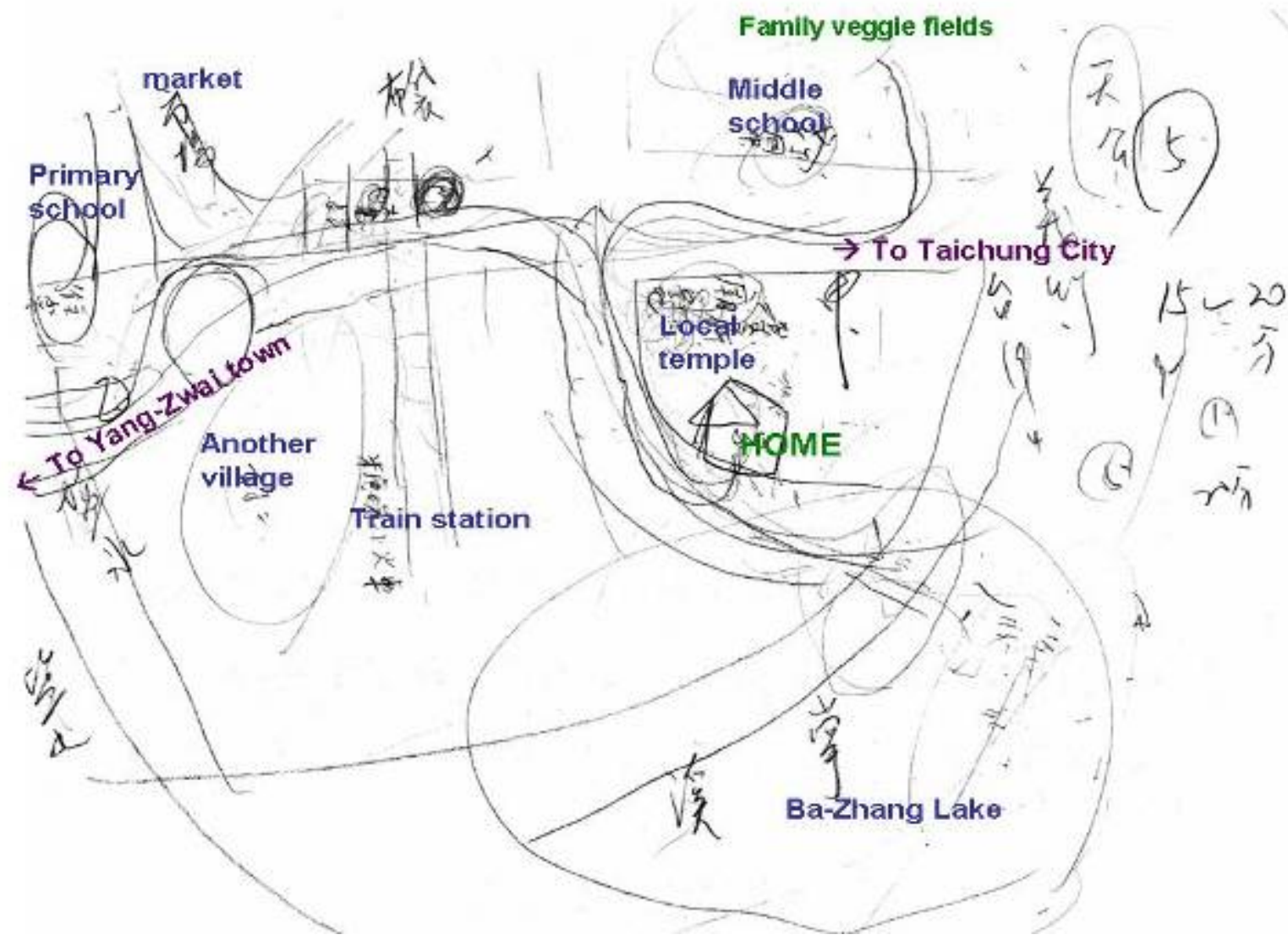

Figure 7. Chi-Lin's drawing of the extension of her childhood lived space

Chi-Lin drew another picture as our conversation had gotten to the point that the san-ho-yuan she drew was no longer enough to illustrate the extension of her childhood roaming experiences. In her drawing (figure 7), she described how she used to play on the nearby lakeside with her childhood friends, how she would go to their family's vegetable fields with her parents, how the community held activities centered around the spiritual practices at the local temple, and how she would pass the train station when she went to and from her school. Chi-Lin's childhood roaming space was not limited to the san-ho-yuan, but extended to a larger space. Although there were many households living in the same san-ho-yuan, Chi-Lin did not consider the different households to be the exterior of her childhood space. Rather, she saw the places that were located a distance from the san-ho-yuan to be on the outskirt of her childhood roaming space - the villages outside of her village, the school and the lake that were a long-walk away, and the market that could be reached via bicycle.

\section{Emerging Similarities Between the Descriptions}

Both Chi-Lin and Li-Mai described their childhood lived spaces as extending outside their family homes, outside the collected architectural compound, and to be part of nature, the animals' lives, and the community. In both Chi-Lin's and Li-Mai's descriptions, the structure of their lived spaces was also experienced as a call for particular types of interpersonal relations. That is, their lived 
spaces called for different kinds of relationships between children and adults, domestic or non-domestic animals, nature, and the social community. In the following sections, the voices of Chi-Lin and Li-Mai are presented to illustrate the different kinds of relationships called for by their childhood lived spaces.

Living with extended family created a chance for both Chi-Lin and Li-Mai to develop a particular kind of close relationship with their grandmothers. Chi-Lin recalled: "As a child, sometimes I stayed at home with my grandmother, I even spent a night with her from time to time. I used to share a bed with my grandmother until I was 12 years old or older.” It did not come across as an unusual practice for Chi-Lin to share a bed with her paternal grandmother or her paternal aunt. She also shared a room with her sister. Regarding her close relationship with her grandmother, Chi-Lin mentioned that her grandmother would sometimes prepare meals for the family because both of her parents had to work at the farm. It is in the subtle practices of shared child care, meal preparation, and labor-intensive productions that the family worked together to support each other organically. It is also in these subtle practices that Chi-Lin had a chance to spend extra time with her grandmother, and thus she had a particular fondness for recalling that time.

Similarly, Li-Mai recalled having a close relationship with her grandmother as a child. She reminisced: "In our small living room, there was a radio for my grandmother to listen to Taiwanese Opera $^{2}$ and I was always there to accompany her.” Greeting the one's elders, especially one's parents in the morning and in the afternoon is a common practice considered virtuous in Taiwan. Li-Mai mentioned that, in addition to greeting her parents, she also used to greet her grandmother every morning before she went to school. Li-Mai's childhood lived space allowed for the practice of greeting elders in the family because her grandmother lived just a few doors away in the same complex. With yearning, Li-Mai recalled the times when her grandmother took her to watch plays in town and on train trips to visit her aunts. Li-Mai mentioned that her grandmother not only played a large part in her childhood leisure activities, but she also greatly influenced Li-Mai's understanding of the value of education. These elaboration of how the felt-distance of childhood space gave rise to a lived experience that echoes Bollnow's (1961) notion that "lived-space must be applied to man who perceives and moves in it” (p. 32).

Chi-Lin developed a special kind of relationship with her grandmother because of the closeness of the lived space and the structure of labor in her family. Chi-Lin's parents were both working on the family farm, and thus her grandmother was in charge of domestic work such as cooking and caring for children. The physical proximity of Chi-Lin's childhood lived space allowed for this division of labor, and Chi-Lin's experience in her childhood lived space produced favorable memories of her grandparents without her necessarily feeling a lack of her parents' presence in her childhood. Li-Mai's close relationship with her grandmother is intertwined with her childhood lived space because her fondness of this memory was recalled as she described her roaming in and out of the spaces in the household. Li-Mai and her grandmother shared a memory in the living room space as they accompanied each other while listening to the opera on the radio. Due to the physical set up of the lived space, both Li-Mai and Chi-Lin had many chances to interact with their grandmothers in educational and leisure settings as they both lived within arm's reach of their grandmothers. The closeness of the lived space for both Chi-Lin and Li-Mei shaped interpersonal relationships in the sense that it facilitated a unique relationship between two non-continuous 
generations - grandmother and granddaughter. This relationship between the two non-continuous generations provided not only the opportunity for the kinds of indulgence of grandparents' wishes that we see in the present day, but it also was experienced as if the grandparents were fulfilling roles similar to parent, educator, companion and leisure partners.

In the participants' description, the children's lived space also bore an inviting intentionality that encouraged engagement with nature, domestic animals and communal activities. When talking about their childhood lived spaces, both Chi-Lin and Li-Mai spoke about their daily engagement with the natural world. The natural environment in children's lived spaces provided materials for children's play, for children's sense of how people make a living, and for imagination. Both Chi-Lin and Li-Mai talked about their play with the giant beefwood tree. Chi-Lin recalled that they made their own swings by tying homemade ropes made from flax (which is also one of the local agricultural products) to the tree. Li-Mai shared that they used to play a game with the seeds of the beefwood tree right outside of her childhood house. (The tree is visible in the bottom left corner of figure 5.) Again, the description of the lived space came alive as the participants described their being in the space that reaches beyond geometrical structure and toward a lived experience.

Due to the agricultural nature of the society, children's sense of how people make a living is connected to their immediate accessibility to their household farm. Li-Mai talked about a room where her parents used to keep all the farming equipment (located next to grandmother's room in figure 5) and she said,

"[o] ther than the fact that this tool room is a place for us (children) to play hide and seek, I also had a strong sense that we cannot be separated from the farming tools. Because they were in contact with the soil and they produced things for us to eat... This feeling is strong. You could even find containers of excrement in there. You sense that they stink, but also discover that they are something useful and that they can be used as fertilizer for the vegetables. We knew that we would have income once these farming utensils go out and work."

Li-Mai's description vividly illustrates the continuity of her lived space and her childhood sense of the world. The lived space of the equipment room is not merely a room full of tools, but also a world in which she and her family lived. The tools were in contact with the soil that produced food and thus potentially carried profits for her family. She acknowledged the importance of that room in connecting to her lived world despite the stinky smell and the seemingly irrelevance of the tools as "dead objects." Li-Mai's description parallels the notion of dwelling that reflects a realization of an individual's living. Bollnow (1961) noted, "To dwell is not an activity like any other, but a determination of man in which he realizes his true essence" (p. 33). This description provides an image of the tool room as a childhood dwelling place while playing "hide and seek" that comes along with the contemplation on the intersubjectively connected lives between one's being and the being of the space containing farming tools.

Chi-Lin also recalled that she used to look after the crops when they were drying in the open space of the house. She explained that neighbors' chickens might eat the drying crops, so it is necessary to have someone watch after the crops and chase the chickens away. In the same way 
that Li-Mai's farm equipment room comes alive to become more than a storage room, Chi-Lin's relationship with the open space and the drying crops come alive in her description of the lived space. Chi-Lin did not view the drying crops simply as objects in the open space of her house. Instead, she saw the importance of protecting such space by watching out for the attack of the neighbor's chicken. It is clear that everything the children did had a lived meaning in the lived space, and thus tools were not just objects, crops were not just food to be eaten, and the open spaces were not just empty places devoid of meaning.

Regarding the experience of nature and its cultivation of imagination and creativity, Chi-Lin recalled,

"When I went to the farm with my parents, I checked with them every once in a while to make sure that they were still somewhere in the farmland, because I've heard many ghost stories and was afraid that I would have been taken away by the ghost."

Li-Mai was also amazed by their childhood creativity in terms of making their personalized toys through the natural materials. She said,

"I don't know. There were so few things at the time, we did not have all the fancy modern toys, but there were still so many things that we were able to play with. Somehow we were able to make our own toys and our own games."

The open space at the farm for Chi-Lin called for imagination. Anything can happen in the open farm for a 10-year-old, and Chi-Lin was very aware of it. Her imagination was cultivated through her interaction with nature and the stories she heard about at the farm. At the same time, her imagination was balanced through her reality checking with her parents' voices. She was at once engaging in her imagination and living in her world with other people and engaging in the mass possibilities at the farm and the stabilized sense of safeness with her parents' mirroring vocal responses. In a similar way, Li-Mai's childhood space also called for an engagement in both imagination and reality. She and her childhood friends invented their play with the materials in the lived space provided by nature. The opportunity of making their own swings or making their own games with what nature had provided was possible because nature was part of their lives. Li-Mai and her friends roamed nature as part of their daily living, and that called for playing creatively with natural materials. This kind of creativity was also tangible because it allowed for Li-Mai and her friends' interpersonal relationships to grow, and it required them to relate to nature in a way that made them realize that the materials and the forces were limited but their imaginations were not. Engaging in nature in the provided lived space seems to cultivate children's creativity and imagination without losing the sense of reality.

Both Chi-Lin and Li-Mai included interactions with domestic animals in their descriptions of their childhood lived spaces. In Taiwan during the 1960s, most households raised domestic animals in close physical proximity to humans’ lived space. Chi-Lin recalled,

"We raised our own cows in the back of the house, and cows like to eat leaves of sugar cane, so sometimes my brother had to go out to our cane farm to slash some cane leaves to feed the cow. I sometimes went with him and fed the cows as well." 
Along the same lines, Li-Mai said,

"We children enjoyed feeding pigs, chicken, and ducks that we raised. Feeding pigs was enjoyable because we knew that we will be able to buy new clothes and shoes on Chinese New Year with it. We fed chickens and ducks with left-over meals. Sometimes as a group, we would wait at the henhouse for their eggs."

The inclusion of domestic animals in the childhood spaces calls for a kind of relating to the animals raised by the family; and the animals were often considered to be part of the family. Feeding cows, pigs, and ducks, and watching the animals laying their eggs were common practices for children who shared a lived space with the animals. The animals were not only a part of adults' lives but they were also a part of children's lives. Children learned what the animals looked like, how they grew, what they liked to eat, and how they reproduced. Children participated in taking care of the animals and learned about their cycles of life as well as how the animals had provided to them. A close relationship with domestic animals seems to have been quite present in a child's daily life in Taiwan during the '60s.

Childhood experiences of communal activities for children in Taiwan in the 1960s was another common way of relating called for by the structural open space in the center of the multiple family households. Li-Mai said explicitly,

"The open space was a place for all the families to get together during holidays, weddings or communal events. For example, during holidays, women would get together in the open space to make traditional foods, and children would stay on the side to check if we could get something to eat. This is the place that consolidates our spirits and gathers us together."

Chi-Lin recalls her childhood summer evening,

"In the evening of summer, children and adults would stay outside at the open space because it is much cooler than indoors. I usually lied down there while adults were talking. Sometimes I played with neighbor's children and my cousins."

For Li-Mai and Chi-Lin, the open space was experienced as a naturally perfect place for communal gatherings and events. It is the place that the families got together to do things and to enjoy each others' company. It was the place for children to mingle with other children and for adults to illustrate their handy-work. Li-Mai especially felt a strong spiritual bond that the open space was able to provide for the connecting and relating that occurred in the community.

Another communal activity that both Li-Mai and Chi-Lin mentioned was the local temple fair. Because children were engaged in a larger community of the town, children also participated in the temple fair that usually took place near their houses. Both Chi-Lin and Li-Mai revealed that children loved to go and see the traditional plays and operas performed during the fair because there were no movies or theaters during those times. The temple fair not only provided a space and a time for communal gathering, it also served as engaging, social entertainment. Growing up in 
such a community in close physical proximity to the local temple (which was identified as one of the childhood roaming places described by both Chi-Lin and Li-Mai), children experienced spirituality seemlessly ,.

The last question that I invited the participants to respond to had to do with their insights on the differences between modern lived space and their childhood lived spaces of 50 years ago. I also invited them to share some personal reflections on how their childhood lived space influenced their personal lives. In response to my question, Chi-Lin said,

"Now land is like gold, almost everywhere it is built with something. Once there is an empty space, something has to be built there. And the spaces are not as open as it used to be, most of them are closed off. We used to share rooms, now every child has to have their own room, and there are also study and other specific functions for different rooms. The outside space was much larger [than now] because too much is built and we no longer have places to walk, play and mingle around. Also now there are more and more cars and motorcycles.”

Li-Mai further implied that as the open space diminishes, people become less neighborly. She said,

"Our open space is now gone because we extended our house over to that open space. The inside of our house used to be much smaller, but now there is no outdoor space after the house was rebuilt. My aunts and uncles all moved away, and we no longer have hens, ducks, and vegetable farms. A creek we used to have has now disappeared maybe because they turned it into street for vehicle traffic. There is no sense of nature anymore. Although we are modernized, people's hearts seem to shrink."

In their reflections, Chi-Lin and Li-Mai both seemed to point to an experience that the extension of private spaces was fulfilled for the price of the loss of the communal space. The absence of communal spaces was experientially similar to an elimination of chances to relate to others in the family, to nature, to animals, and to the world. The shrinking of the lived space echoes the shrinking of people's hearts and the spiritual connection with the world.

\section{Thematic Analysis and Discussion}

Benswager (1979) proposed a three-phase structure by observing children's lived spaces. In order to portray children's lived space in rural Taiwan during the 1960s, I organized the participants' descriptions around this three-phase structure - the themes of space, the perspectives of inhabited space, and modes of relatedness.

Benswager (1979) suggested that the themes of children's lived space could be classified into four categories: attuned space, activity, spatial characteristics, and organization. Children are attuned to the "mood or feeling tone" (p. 116) of a space, and the tone of the space changes depending on the situation. For example, when Chi-Lin described her experience of working on the farm with her parents, she "checked with [her parents] every once in a while to make sure they 
were still somewhere in the farmland.” The mood and feeling of the farmland was very different for Chi-Lin at age 10 when she could not be sure that her parents were around. In terms of the theme of activity, Benswager (1979) indicates that activity involves movement for or to which a child is called. In 1960s Taiwan, the nearness to the natural world called children to participate in the rhythm of nature. Both Chi-Lin and Li-Mai shared their experience of using natural materials in their childhood play. For example, playing with the seeds of the tree or in the natural spaces around them came to them very readily when they were growing up. Also, the open space of san-ho-yuan called children to participate in many communal events and to be part of the adults' world. As for spatial characteristics, a permeable boundary was described in children's lived space in 1960s Taiwan. For example, Li-Mai and Chi-Lin both reported that they shared a bedroom with their siblings as a child. Even if they did not share a room with their siblings, they were used to sharing the bed with their grandmothers or aunts. A sense of privacy or individuality was rarely mentioned and their described spatial experiences appeared to be lived intersubjectively via this shared feeling of lived space.

Moreover, Chi-Lin and Li-Mai's childhood roaming spaces were not limited to their own households. They were free to go in and out of their relatives' households, to play with neighbors and siblings, and to engage in activities in the larger community. For children in 1960s Taiwan, the spatial characteristic of their lived space was free, open, and accommodating. Regarding the organization of children's lived spaces, Benswager (1979) suggests that a primary caretaker usually serves as the "anchorage" for children in situating their lived spaces. It is worth noting that for both Li-Mai and Chi-Lin, their primary care-taker was not their mother as a single entity. They both revealed a unique relationship with their grandmother and shared experiences with other older children or stay-at-home relatives. This phenomenon suggests that during the 1960s in Taiwan, children's organization was centered on the collaboration of their family members instead of merely the biological mother as a single responsible care-taker. This way of organization is only possible when the structure of the lived space is arranged such that the extended family lives close enough to one another. It is possible that children in 1960s Taiwan identify themselves closely with their family of origin as a whole but not a separate individual entity.

According to Benswager (1979), "every spatial act reflects [the] pervasive intertwining of self-act-world” (p.119). For children, their inhabited space represented perspectives from the self, from their act, and from the world. Take Li-Mai's description of feeding domestic animals for example, she first reflected from her own perspective in the following: "We children enjoyed feeding [domestic animals] that we raised." She then described the perspective of the world by indicating that domestic animals were part of the worldly presence that provided children with new clothes during the Chinese New Year. She said, "[f]eeding pigs was enjoyable because we knew that we would be able to buy new clothes and shoes on Chinese New Year.” Lastly, she engages the perspective of the act by stating: "[w]e fed chickens and ducks with left-over meals." In the above example of Li-Mai's experience, it is obvious that the intertwined perspectives of self-act-world are part of her understanding of her childhood lived space. That is, her description of her childhood space is no longer of a physical place but a space that contains a world of acting and engaging with others. Merleau-Ponty's (1968) understanding of the lived world is in accordance with Benswager's idea that considers a lived space as an intertwining of self-act-world. 
Merleau-Ponty views the lived world as both seeing and seen, acting and acted upon, and experiencing and experienced. Thus a person is always already engaged in the self-other relationship in the world. In Li-Mai's childhood lived world, she was at once seeing and seen by the domestic animals, at once feeding and being fed by the animals, and at once influencing and influenced by the animals. As such, her childhood lived space was a "pervasive intertwining of self-act-world" that always already engaged in acting and being acted upon.

Benswager (1979) proposes that the third phase - modes of relatedness - of his structural model of lived space encompasses two dimensions: presence and transcendence. The mode of presence reflects attachment to the lived world, resonance, trust and familiarity. It serves the function of coherence and continuity for children. On the contrary, the mode of transcendence reflects the otherness of the lived world, dissonance, and the implication of a differentiated world. It allows for the emergence of identity formation in children. Benswanger (1979) said that "[t]he modes of relatedness express the distinct but interdependent polarities of human existence. For the subject, there is always the contrapuntal movement between self and world, continuity and change, attachment and separation” (p. 120). For children in Taiwan during 1960s, they had on the one hand the resonance of extended family that invited them to engage in various communal activity, and on the other hand, plenty of chance to adventure into the natural world including farms, trees, creeks, animals, etc. Children were free to navigate between the need to be "close, attached, and embedded” and the need “to be separate and distinct” (Benswanger, 1979, p. 120).

The complex relationship of these interdependent polarities with the dimensions of presence and transcendence implies that it is important to experience both dimensions fully without being entirely fixed on either one of them. Children's lived spaces in Taiwan during 1960s contained the interdependence of presence and transcendence for the children. On the other hand, Chi-Lin suggested that, instead of sharing a space with others, children nowadays often have their own private room. This privacy diminishes the opportunity for them to be close and attached to other people. In other words, children in the modern Taiwan are given more chances to be separate and distinct, yet they lack the opportunity to experience being close, attached, and embedded in a safely- and closely-knitted family. Since presence and transcendence dimensions are interdependent, children nowadays may have more difficulty to engage in the dimension of transcendence because they have not experienced the presence dimension fully.

\section{Conclusion}

Langeveld (1983) said that "[t]he lived experiencing of space is dynamic; space is 'created' personally" (p. 189). To understand the dynamic and the creative nature of the lived spaces for children in rural Taiwan during the 1960s, the present study explored children's lived spaces through the participants' descriptions of their experiences as a child growing up in those spaces. From the descriptions of the participants, children's experiences of lived spaces are informed by san-ho-yuan architecture that houses the children's immediate and extended family. Such architectural structure (of children's lived space) has an open space in the center that invites an intimate familial encounter, engagement with nature and domestic animals, and communal activities in the society. In addition, Benswanger's (1979) three-phase structure provides a portrait of the interconnected nature of children's lived space. The participants' reflections on children's 
lived space between the 1960s and the present suggests an imbalance between the mode of presence and the mode of transcendence for children today. Benswanger (1979) noted that "[f]or [normal, healthy] children, space seems to be infused with a sense of reality... space is the means whereby the positing of things and self becomes possible” (p. 120). The creative play with limited materials performed by children in Taiwan in the 1960s suggests their ability to engage in their imagination without losing contacts to the reality. However, modern society provides isolated lived space to children that allows for little variety of relating. Children in the modern society are stripped of opportunity to relate to their extended family members, to their neighbors and cousins, to domestic animals, to nature, and to the community. If Benswanger is right about the interdependent nature of presence and transcendence, then the isolated space that forces children into the transcendence dimension of separation is counterproductive. For without the presence dimension - that is, closeness, attachment, and embeddedness - children cannot relate to the world in the transcendence mode either.

I will conclude by calling attention to the following questions: How does the evolution of childhood lived space change children's being-in-the-world? How does the being of children change as their lived spaces vary? Do these changes of childhood lived space make it impossible for children's positing in the world? How may we understand the implications of the impossibility of children's positing in the world differently and thus open up more possibilities? In the same token, what may be the challenges for children nowadays to forming their sense of identity in a given lived space?

\section{Endnotes}

${ }^{1}$ All names of participants in this paper have been changed to protect their privacy.

2 Taiwanese opera is a crystallization of popular culture that originated in Taiwan. More information: see www.edu.ocac.gov.tw/culture/chinese/CULTUREENGLISH/Folkore/Ewhole02 _16.htm.

\section{References}

Benswanger, E. G. (1979). A contribution to the phenomenology of lived-space in early childhood. In A. Giorgi, R. Knowles, and D. Smith (Eds.), Duquesne studies in phenomenological psychology Volume 3 (pp. 111-121). Pittsburgh, PA: Duquesne University Press.

Bollnow, I. F. (1961). Lived-Space. Philosophy Today, V, 31-39.

Langeveld, M. J. (1983). The secret place in the life of the child. Phenomenology \& Pedagogy, 1(3), 181-189.

Minkowski, E. (1970). Lived time: Phenomenological and psychopathological studies. Evanston, IL: Northwestern University Press. 
Merleau-Ponty, M. (1962). Phenomenology of perception. London: Routledge and Kegan Paul.

Merleau-Ponty, M. (1968/2000). The visible and the invisible. Evanston, Il: Northwestern University Press.

Simms, E. (2008a). Children's lived space in the inner city: Historical and political aspects of the psychology of place. Humanistic Psychologist, 36(1), 72-89.

Simms, E. (2008b). The child in the world: Embodiment, time, and language in early childhood. Detroit, MI: Wayne State University Press. 